\title{
빈곤의 정의: 다면성과 측정의 한계
}

김지현(KOICA ODA연구팀 연구원)

목 차

I. 서론: 빈곤이란 무엇인가? 왜 정의해야 하는가?

II. 빈곤에 대한 개념화와 다양한 정의

1. 빈곤에 대한 개념화(Conceptualization of Poverty)

2. 절대빈곤과 상대빈곤

3. 빈곤의 정의와 빈곤퇴치에 관한 접근

III. 빈곤의 측정 방식과 한계

1. 양적 측정 방식(Quantitative Measurements)

2. 질적 측정 방식: 소득 이외의 지표

IV. 결론

\section{I. 서론: 빈곤이란 무엇인가? 왜 정의해야 하는가?}

"The poor will always be with you"(Matthew 26:11)

"This post-2015 agenda must have poverty eradication as its highest priority..."

(Ban Ki-Moon, 2013)

본 연구 자료는 빈곤(poverty)의 원인과 해결에 관한 주요 이론들을 조망하고 빈 곤의 정의 변화 흐름을 소개하는 것을 목적으로 한다. 빈곤 퇴치는 개발도상국의 발 전이나 경제성장에 관심을 두고 있는 모든 사람들에게 가장 핵심적인 고려대상이 되 고 있다. 지난 2000 년 이후 개발협력의 국제규범으로 자리잡아온 새천년개발목표 (Millennium Development Goals, 이하 MDGs)의 주요 목표도 2015년까지 빈곤을 
절반 수준으로 감소하는 것이며, 그 방법도 부채탕감에서 거시경제안정화에 이르기 까지 다양하게 제시되어 왔다. 그리고 이러한 빈곤 종식은 Post-2015 개발의제를 수 립하는 과정 속에서도 향후 국제개발협력의 큰 화두가 될 전망이다.

그러나 모순적이게도 빈곤의 감소를 강조함과 동시에 공여국을 비롯한 국제사회에 서 빈곤의 의미에 대한 논란은 지속적으로 심화되어 오고 있다. 빈곤이란 무엇인가? 빈곤을 개념적으로 어떻게 정의할 것인가는 오랫동안 정치적으로도 정책적으로, 그 리고 학문적으로도 중요한 이슈가 되어왔다. 그렇다면 이 시점에서 우리는 왜 빈곤 이란 무엇인가에 대한 물음을 다시 상기해야 하는가?

우선 첫째, 빈곤의 정의에 따라 그 해소의 방법/정책이 변화되기 때문이다. 단순하 게 예를 들어 빈곤을 소득의 부재 또는 결핍으로 정의한다면 소득 증대를 위한 정책 을, 빈곤의 원인을 불평등에서 찾는다면 사회의 분배구조를 개혁하는 정책을 수립해 야하는 등 해법을 찾는 과정이 정의에 따라 상이하기 때문이다. 둘째, 빈곤의 정의에 따라 다른 방식의 정책이 수립될 수 있고 이러한 정책의 효과성을 모니터링하고 평 가할 수 있는 측정방식이 달라져야 하기 때문이다. 따라서 빈곤에 대한 해결책을 논 하기 앞서 우리는 빈곤의 개념과 정의, 측정에 대한 심도있는 논의와 사회적 합의가 선행되어야 한다. 새로운 시대에 맞는 새로운 개발의제가 논의되고 있는 시점에서 빈곤에 대한 다양한 관점과 측정방법 등을 재조명해봄으로서 우리의 전략과 $\mathrm{ODA}$ 정 책 방향성을 제고할 수 있는 기회로 삼고자 한다.

이를 위해 본고는 다음과 같이 구성되어있다. 제 2 장에서는 빈곤의 정의에 관해 이 루어졌던 기존의 연구들을 살펴보고 주요개념을 정리하였다. 제 3 장에서는 제 2 장에서 다루어졌던 빈곤의 정의에 따른 다양한 측정방식을 살펴보고, 각각의 지표가 의미하 는 바와 그 한계를 분석한다. 마지막으로 제 4 장의 결론에서는 빈곤의 새로운 정의와 관련한 최근의 논의를 대해 소개하고 향후 전략방향을 생각할 수 있는 계기를 마련 하고자 한다. 


\section{II. 빈곤에 대한 개념화와 다양한 정의}

\section{1. 빈곤에 대한 개념화(Conceptualization of Poverty)}

빈곤의 개념이라 함은 사회의 특정 그룹들이 다르게 느낄 수 있는 빈곤의 의미를 말 한다. 예를 들어 빈곤은 '기초안전이 보장되어 있지 않다' 또는 '기본권을 누릴 수 있도 록 하는 요인들 중 하나 이상이 결여되어 있는 상태'를 의미하기도 한다(Spicker 1999: 153). 따라서 빈곤 개념에 대한 연구는 빈곤담론으로 이어져 실제로 빈곤을 경험하는 사람들보다 좀 더 다수의 비 빈곤층이 가진 빈곤에 대한 이미지인 경우가 많다.

빈곤을 정의하는 일은 결코 쉽지 않다. 그래서 빈곤에 대한 여러 가지 정의가 가 능하고 이를 기반으로 한 다양한 정책이 개발협력분야에서 시도되고 있다. 빈곤에 대한 정의는 소득 또는 소비(구매) 기반에서부터 빈곤의 각종 징후를 통해 다면성을 강조하는데 까지 다양하다. 이러한 여러 가지 징후들은 각각의 의미가 있는데 대표 적으로 생계를 지속할 수 있는 생산 자원부족, 물/보건/교육 등 기본서비스에 대한 접근 부재 또는 제한적인 접근, 기아와 영양실조, 사망률과 사망자 수의 증가, 불안, 주거공간의 부재 또는 취약한 주거 공간, 사회/문화/정치 활동에 참여 부족, 사회적 차별과 소외(Estivill 2003) 등을 제시할 수 있다. 이들 각각의 징후들은 서로를 더 심화시킨다. 예를 들어 기아는 영양실조를 야기할 수 있으며, 이는 결국 질병발생으 로 이어질 수 있다. 또 만성질환은 개인의 사회활동 참여를 제한하고 이는 결국 사 회적 소외와 빈곤으로 이어지게 된다.

따라서 Klugman(2002)는 빈곤을 정의하기 위해서는 어떤 사회에 적용해도 빈곤 계층을 정의할 수 있는 최소한의 기준이 필요하다고 주장하기도 했다. 이러한 최소 기준은 즉, 빈곤선(poverty line)은 최저생활에 근거하여 책정되었으며, "물리적으로 인간의 삶을 유지하기 위한 물질적인 자원이 없다면 그 사람들은 빈곤상태이다 (Haralambos, Holborn \& Heald 1991:191)."는 단순한 가정에 의해 수립되었다. 현 재의 빈곤과 빈곤선의 정의도 이러한 연장선상에서 합당한 사회적 기준 또는 한계선 (threshold) 이하의 삶으로 정의되고 있다고 볼 수 있다(Klugman 2002). 그러나 실 제로 많은 학자들이 이러한 최소한의(보편적인) 기준을 빈곤을 정의하는 데 사용하는 
것은 옳지 않으며, 빈곤은 그 자체로 특정한 사회 내, 특정한 시점에서 정의되어야 한다고 주장하고 있다(Lauer 1998 등). 이런 관점에서 보면 빈곤선 자체가 그 사회 가 얼마나 부유한지에 따라 다양하게 나타나야 한다.

그러나 적어도 빈곤은 개인이나 특정 집단이 삶의 웰빙을 추구하는데 있어 필요한 역량/자원이 박탈(deprivation)된 발생한 상태라는 것에 대해서는 동의할 수 있을 것 이다. World Bank(2001)은 빈곤은 물질적이거나(소득, 기초 서비스 등), 물질적이지 않은 요소(취약성, 발언권부재, 무기력, 정신 질환 등) 등을 모두 아우르는 박탈이라 고 정의하고 있다. Narayan(2002)에서는 빈곤은 웰빙이 박탈당하고, 자신이 통제할 수 없는 일들에 취약하며, 고립되고, 합당한 정도의 사회경제적 규범 이하의 삶을 살 며, 정신적으로나 정치적으로 불능인 상태로 규정하고 있다. Ringen(1987)은 빈곤을 '낮은 생활수준'을 갖은 것으로 정의하면서, 이러한 박탈을 피할 수 있는 역량을 갖 출 수 있는 자원의 부족 상태로 설명하고 있다. 결국 이러한 박탈과 상호작용하는 빈곤은 낮은 생활수준과 소득에 기인하게 된다. World Bank의 2001년, 2008년 보 고서는 소득에 기반한 빈곤의 개념화를 보여주고 있다. 특히 2008년 보고서에서 World Bank는 하루 US\$2 빈곤선 이하의 인구와 US\$1.25 극빈 인구를 구분하면서 소득을 최우선 측정 자료로 활용했다. 이러한 빈곤선 이하, 최빈층 등의 구분이 바로 빈곤의 절대적 측정이다(예를 들어, 특정 기준선 이하의 삶을 사는 인구수와 비중 등). 따라서 World Bank는 빈곤을 기본욕구를 충족하기 위한 최소수준 이하의 소득 수준으로 보고 있다. 이러한 소득 수준이 '빈곤선'이며, 이는 국가/사회/시기별로 다 양하게 수립될 수 있다.

\section{2. 절대빈곤과 상대빈곤}

절대빈곤과 상대빈곤의 구분은 빈곤을 어떻게 정의할 것인가에 대한 논쟁 중 가장 오랜 역사를 가지고 있다. 19세기말에서 20세기 초까지 Booth와 Rowntree로부터 ‘절대’빈곤은 물리적인 기본욕구를 충족시킬 수 있는 정도의 돈이 없는 것으로 이해 되었다(Rowntree 1901). 가장 기본적으로 절대빈곤은 생존과 직결된 상태, 최저생계 와 이를 위한 생산 및 재생산 활동에 필요한 물리적 역량과 연계되었다. 따라서 영 양(nutrition)은 이러한 정의에서 중심개념으로 인식되었으며 '먹을 것을 구하지 못 
하는 정도라면 그 가족은 빈곤하다(Joseph and Sumption 1979:27)'과 같은 정의를 낳기도 했다. 좀더 최근에는 절대빈곤과 상대빈곤은 박탈의 정도에 따라 구분하고 있는데, 절대빈곤은 절대적인 최소기준 이하를 상대빈곤은 속해있는 사회에서 대부 분의 타인들 이하의 삶으로 정의할 수 있다(Lauer 1998:212). De Beer and Swanepoel(2002)는 절대빈곤은 소득은 낮고, 최소한의 생활수준이 유지되기 어려운 상황으로 정의했다. 네팔의 $\mathrm{MDGs}$ 보고서에서는 절대빈곤은 “최소한의 식량을 구하 기 어려운 소득수준(UNDP 2013)"으로 정의하였다. 이는 World Bank에서 제시한 하 루 US\$1.25의 빈곤선 이하의 삶을 의미하는 것이다.

이에 대해 상대빈곤은 Townsend에 의해 개념화되었다. Townsend(1979)는 사회적 관점을 배제한 기본적인 욕구를 최저생계기준으로 삼는 정의를 비판하면서, '상대적' 인 것에 대한 정의를 다음과 같이 내리고 있다;

먹을 것을 구할 때, 관습적인 활동에 참여하거나 적어도 자신이 속해있는 사회에서 인정 되는 삶의 환경을 유지하려할 때, 이를 가능하게 할 수 있는 자원이 부족할 때, 전체 인구 내에서 해당 개인과 가족, 집단은 가난하다고 할 수 있다. 이 자원이 심각할 정도로 부족하 여 일반적인 생활양식과 활동으로부터 배제되는 것을 의미한다(Townsend 1979:31).

Townsend의 정의에서 주목해야 할 부분은 사회참여이다. 결국 빈곤의 핵심은 '상 대적 박탈'이며 이러한 상대적 박탈이 사회 안에서의 역할을 제한하고, 정치활동에의 참여, 관습적인 행동에서의 배제를 촉발하기 때문이다(Townsend 1993). 상대적 빈 곤은 따라서 필수품을 얻기 위한 경제적인 자원이 부족해서가 아니라 부족하다고 느 끼는 상태를 말한다. 상대적 빈곤층은 일반적으로 생활이나 건강이 즉시 나빠질 정 도로 빈곤하지는 않지만 그 사회의 대다수 사람들, 관습적인 생활을 영유하는 사람 들에 비해 빈곤하여 기타의 사회경제적인 빈곤징후를 보이게 되는 상태를 의미한다. 따라서 동일한 기준에서 상대적 빈곤을 정의하는 것은 불가능하며 각 국가와 사회마 다 그 의미와 정도가 달라진다.

절대빈곤과 상대빈곤 이외에도 여러 가지 구분이 존재한다. Rowntree(1901)은 일 차적 빈곤(primary poverty)와 이차적 빈곤(secondary poverty)로 구분하면서 일차 
적 빈곤이 그가 설정한 빈곤선 이하의 삶을 사는 인구를 지칭하며 이들은 “재정적 자 원이 충분하지 순전히 물리적인 삶을 유지하는데 필요한 최소한의 필요조건을 얻기 위한 재정적인 자원이 충분하지 못한(Rowntree 1901:298)” 것으로 특징지었다. 이차 적 빈곤은 일차적 빈곤과는 달리 소득 면에서 보면 빈곤선 이상이나 필수품 이외의 물품에 소비(사치품 구입, 도박 등)를 함으로서 빈곤선 이하의 삶을 유지하고 있는 것으로 구분하였다. Rowntree의 이러한 구분은 20 세기 초 중소도시의 경험적 조사 를 근거로 한 객관성이 입증되지 않은 연구라는 비판에도 불구하고 소득과 소비양태 모두를 빈곤의 정의에 포함하려 했다는 점, 그리고 필수품 소비의 기준을 마련하려 하였다는 점에서 의미가 있다.

또한 일부 학자들은 실제적 빈곤과 잠재적 빈곤을 구분하기도 하는데 이는 '회복 력'과 관련이 있다. 소규모 낙농업자와 같이 현재 소득수준으로는 빈곤하지 않으나, 가뭄과 같은 일시적인 충격(shock)이나 계절적 요인(seasonal events)에 취약성을 보이며, 충격을 극복하고 이 전의 상태로 회복하기 매우 어려운 상태에 있는 인구도 잠재적 빈곤층으로 보아야 한다는 점을 강조하고 있다(Mullin and Arce 2008). 이 러한 구분에 의하면 잠재적 빈곤층에 대한 정책은 지금 현재 빈곤상황을 극복하기 위한 정책과 함께 장기적으로 일상생활에서 일어날 수 있는 위험요소도 고려해야 한 다. 장기적인 관점에서의 빈곤에 대한 접근은 지속적 빈곤(Chronic poverty)과 일시 적 빈곤(Transitory poverty) 구분과도 연관될 수 있다. 일시적 빈곤은 빈곤층이 아 니었던 계층 또는 개인이 일시적으로 가난해졌다가 짧은 기간 내에 다시 빈곤층을 벗어나는 경우를 의미하며, 반대로 지속적인 빈곤은 가난의 대물림을 의미한다.

\section{3. 빈곤의 정의와 빈곤퇴치에 관한 접근}

\section{1) 경제적 기준 빈곤(Monetary Approach)}

빈곤에 대해 일반적인 개념들은 화폐적 혹은 소득/소비 접근법이다. Lipton (1997:127)은 소득/소비 접근법을 개인은 특정 시기에 관계없이 자원에 대한 접근성 이 충분하지 못할 때 가난하며, 기초 필요를 충족시키기 위한 필수품이 있어야 한다 고 정의하고 있다. 이런 연장선상에서 경제적 기준의 빈곤은 소득이나 소비를 만족 
시킬 수 있는 자원과 연관성을 갖게 된다. 소득과 소비 기준에서 '빈곤층'이란 소득 이나 소비가 빈곤선 이하인 사람들을 지칭한다. 빈곤선은 최소한의 소비와 개인(가 계)이 생존에 필수적인 것들을 파악하기 위해 설정되며, '빈곤층'이란 소득이나 소비 역량이 최소한의 필요로 정한 빈곤선에 이하의 삶을 영위하는 사람들을 일컫게 된다. 이러한 접근법에서는 생존에 필요한 최소한의 가치를 평가하는데 초점을 두면서 소 비를 측정하게 된다(Ravallion 1994).

이러한 경제적 접근법은 정책 분석에 유용하게 활용되는데, 이는 모든 가구들이 기본적인 필요가 채워질 때까지 지속적으로 노력할 뿐만 아니라, 이를 위해 자원을 획득하고 사용함을 전제하기 때문에, 정책입안자들은 사회의 빈곤을 지속적으로 관 찰하고 평가할 수 있다. 또한 광범위한 국가에 걸쳐 국가적 차원의 빈곤 발생과 그 에 따른 대책을 모색할 수 있다는 장점이 있다(World Bank 2001). 그러나 경제적 접근법의 결함도 간과할 수 없다. 측정방법 상의 한계1)와 함께 빈곤이라는 것이 경 제적 현상만이 아니며, 경제적인 관점만으로 사회적 불균형을 파악하기는 불충분하 다는 한계를 내포하고 있다. 다시 말해, 경제적 빈곤은 빈곤의 한 단면이며, 빈곤의 원인과 결과물들도 고려해야한다. 또한 빈곤층이 아닌 사람들이 만들어낸 기준에 따 라 측정되기 때문에 빈곤층의 현실적인 필요를 반영하지 못할 수도 있다는 한계가 지적되기도 한다.

\section{2) 역량 기준 빈곤(Capability Approach)}

Amartya Sen의 필두로 역량기준 또는 인간개발(human development, HD) 패러 다임은 사회경제적 이슈에 대해 전체주의적 접근을 시도하였다. $\mathrm{HD}$ 패러다임에서는 소득의 부족과 이로 인한 소비결핍이 빈곤의 한 원인이지만, 보다 근본적으로는 구 조적인 빈곤을 야기하는 사회체계에 주목한다. 사회간접자본의 부족 그리고 성 평등, 사회시스템의 불완전성, 그리고 일자리의 부족 또한 빈곤의 원인이다. Sen은 빈곤은 낮은 소득을 의미하는 것은 아니며 “기본적인 역량의 박탈(the deprivation of basic capabilities)" 이고, “개인의 소유한 역량이란 가치 있는 삶을 영위하기 위해 누리는 실질적인 자유”라고 주장했다(Sen 1983). 따라서 빈곤은 육체적이거나 물리적인 기

1) 이와 관련한 내용은 제3장에서 좀 더 자세하게 다루도록 한다. 
초자원이 부족하다는 것 이외에도 사회경제적 활동을 위한 도구(tool)와 능력 (capacity)의 부족을 의미한다. 여기에서의 기본역량이란 “결정적으로 중요한 요소들 을 최소한의 수준까지 만족시킬 수 있는 능력”으로 정의되고(Sen 1999), 국가와 정 책의 역할은 이러한 기본적인 역량을 개인이 배양할 수 있도록 기회를 제공하고 기 초적인 자원에 대한 접근성을 강화하는 것으로 제안하고 있다.

역량 접근법은 경제적 접근에서 다루고 있는 기초 필수품뿐만 아니라 그것을 유지 하고 이를 생산적인 역량으로 발전시킬 수 있는 능력을 빈곤의 정의로 보면서, 이와 함께 빈곤으로의 회귀에 대한 대응도 고려하고 있다는 점이다. 또한 역량 (capability)을 빈곤의 화폐적인 측면뿐만 아니라 사회적 · 정치적 측면에 주목했다는 데에 있어 의의가 있다. 빈곤의 개념이 빈곤으로 인해 발생하는 문제(결과물)와 사회 개발을 포함하는 것은 매우 의미 있는 일이며, 측정에 있어서도 개인의 전반적인 복 지에 집중하게 되므로 이러한 정의에 의해 빈곤 완화의 결과가 소득의 증대, 건강 뿐만이 아니라, Human Capital 개발을 위한 제도 확립의 중요성을 강조한다는 점에 서도 의미를 찾을 수 있다.

그러나 빈곤을 분석하기 위해 역량 접근법을 사용하는 데에 있어 많은 주의가 필 요한 것도 사실이다. 역량 접근법이 빈곤의 재정적인 측면을 분석하는데 그치지 않 고, 만족을 이끌어 낼 수 있는 역량에 주목하는 것은 그 의미가 크긴 하지만, "기초 적인 역량”을 무엇으로 정의할 수 있는지가 또 하나의 논쟁거리를 만들어 내고 있다. $\operatorname{Sen}(1983)$ 의 연구는 일반적인 요소들을 포함하고 있기는 하지만 최소한의 역량을 구 체적으로 제시하지는 않는다. 또한 “좋은 삶(good life)”이나 “웰빙(well-being)”은 서구적인 개념을 차용하는 경우가 많아, 단순히 소득소비 접근법의 기본 항목과 겹 치는 경우가 많이 있다. 또한 '역량'을 정의하기가 어렵기 때문에 실제 역량보다는 '역량의 차이로부터 나오는 결과물(outcome)'을 측정할 수밖에 없다. 예를 들어 질병 의 영향과 질병 관리 역량을 측정하기 위해서 기대수명 또는 영아 사망률, 생각의 자유나 비판적 사고 역량을 측정하기 위해서 문맹률을 기준으로 하는 것과 같다.

또한 역량 접근법에서는 사회를 평가하는 데 있어 삶의 질에 영향을 미치는 물질 적인 조건들은 배제되고, 사람들의 심리적 성향이 중요한 역할을 감당하게 된다. 그 
결과 건강하고 수입이 좋은 사람들이 그들의 상황에 만족하지 못 할 수도 반대로 건 강치 못하거나 기술이 부족한 사람들이 자신들의 삶에 만족할 수 있는 상황을 추적 하지 못하는 등 역량을 근거로 빈곤을 측정하는 것은 도전적인 시도이기는 하나 더 많은 검증을 필요로 한다.

제 I장

개

\section{3) 사회적 배제 기준 빈곤(Social Exclusion Approach)}

또 다른 접근은 불평등과 사회적 배제이다. 이는 상대적 박탈감, 소득불평등에서 비롯되는 빈곤이며, 신 빈곤으로 정의되기도 한다. 2000년 이후 유럽을 중심으로 빈 곤의 위협과 사회적 배제를 겨냥한 전략적인 목표와 정치적인 절차들이 도입되었다. $\mathrm{EU}$ 는 사회적 배제를 개인과 집단이 그들이 속해있는 사회활동에 참여함에 있어 전 반적이거나 부분적으로 배제되는 과정(process)로 규정하였고(EC 2004), 이러한 접 근법은 다양한 국제기구의 활동을 통해 개도국의 빈곤을 규명하고 설명하는데 까지 확대 사용되었다.

Townsend의 사회적 박탈 정의와 함께 Le Grand는 사회적 배제가 개인이 통제할 수 없는 이유로 기타 일반 사회구성원들의 활동에 참여할 수 없는 것으로 정의하면 서 '그가 원하냐의 여부와 무관하게' 동참하지 못하는 것이 사회적 배제라고 주장했 다(Le Grand 1991). 사회적 배제는 상대성(relativity), 행위의 주체(agency), 역동 성(dynamics)의 특징을 가지고 있는데(Atkinson 1998) 이는 사회마다 배제의 의미 가 다르며, 구성원의 행동으로 인해 생겨나고, 현재뿐만 아니라 미래의 변화에도 영 향을 미친다. 즉, 이 접근법에서는 박탈에 이르는 과정이 중요한 고려사항으로, 빈곤 에 처해지는 과정과 박탈의 결과물에 주목하고 있다. 뿐만 아니라 이 접근법은 소수 민족, 노인, 장애인과 같이 개인보다는 특정 집단에 대한 연구가 다양하게 이루어지 는데, 그 결과 이를 기초로 차별을 근절하는 정책 등과 같이 집단적인 개념을 다루 고 있어, 정책적 접근이 쉬운 장점을 가지고 있다.

그러나 무엇을 배제로 볼 것인가는 다른 접근법과 마찬가지로 논쟁의 여지를 남긴 다. 어떤 사회에서는 사회체제의 일부분으로 배제 자체가 존재하기도 하다. 이러한 맥락에서 볼 때, 개별 사회에서 배제가 무엇인가를 규명하기 위해서는 빈곤 당사자 
의 참여가 필요하다. 앞서 밝힌 바와 같이 빈곤이 '빈곤하지 않은 사람들'에 의해 정 의되는 경우가 대부분이고 사회적 배제 역시 이런 문제에게 자유롭지 못하다.

이러한 문제점들이 존재함에도 불구하고 사회적 배제 접근법은 박탈발생 원인과 과정에 주안점을 두는 방법이다. 경제적 접근법과 역량 접근법이 개인과 상황에 초 점을 맞추는 것과 달리 사회적 배제 접근법은 사회의 구조적인 특성을 원인으로 파 악하여 사회 내 특정 집단이 처한 상황에 대한 분석과 이를 통한 해결책 모색을 가 능하게 해준다.

(1) 참여적 접근(Participatory Approach)2)

그러나 빈곤의 정의는 빈곤층의 필요를 고려하기 보다는 빈곤을 정의하고 측정하 는 개인의 선호를 배제할 수 없다. 위에서 지적된 바와 같이, 경제적 접근법과 역량 접근법은 빈곤의 원인이나 역동성에 대한 고려 없이 빈곤층 의 판단이 배제되었다는 것에 대한 비판을 받아왔다. Chamber에 의해 제안된 참여접근법은 빈곤의 정도나 그 의미를 결정하는 데에 빈곤층이 참여하는 것이 중요하다고 보았다(Chamber 1995).

이론에 의하면 '참여에 의한 빈곤 평가'에서 빈곤을 정의하는 것뿐만 아니라 그 해 결책을 찾는 과정에서도 주체는 지역주민이다. 그러나 외부인의 참여, 특히 평가 시 참여는 불가항력적이다. 참여 접근법의 또 다른 문제점은 집안 안에서의 차이를 간 과한다는 것이다. 집단를 구성하는 모든 요소가 동일한 경우가 아니라면, 다양한 의 견과 관점이 반영되어야 한다. 그러나 참여 접근법은 그 사회의 권위자들에 의해 조 정당하기도 한다. 그러므로 참여 자체에 배제된 구성원의 의견을 반영하지 못하거나, 대표자들을 선정하는 데 있어서 어려움이 뒤따른다.

2) 많은 연구나 교과서에서 참여적 접근을 분리하여 빈곤을 정의하는데 4 가지 접근이 있 다고 기술하고 있다. 그러나 저자는 참여적 접근은 빈곤과 비 빈곤을 가르는 기준 즉, 소득/소비, 역량, 배제 등을 정함에 있어 빈곤층의 참여가 중요하다고 강조한다는 측면 에서 보면 앞의 3 가지 접근은 개념적 요소를, 참여적 접근은 방법론적인 요소를 강조 하고 있다고 보아 3-1로 분류하였다. 
빈곤을 이해하고 측정하기 위해 전적으로 참여 접근법에 의존하는 것의 또 다른 문제점은 집단 구성원이 갖는 정보와 사회 환경 정보의 객관성 보장이 어렵다는 것 도 한계로 지적되고 있다.

제I장

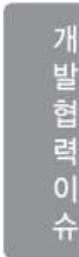

제I장

제III장

제IV장

- 빈곤선(Poverty Line): 특정 국가에서 적합하다고 여겨지는 최소 수준의 소 득(Ravallion 1992). 국가 간 비교를 위해 WB에서 2008년에 2005년 구매 력평가지수(Purchasing Power Parity, PPP)를 기준으로 하루 US\$1.25으로 조정한 바 있다(Ravallion et al. 2009).

- 빈곤의 덫(Poverty Trap): 빈곤을 지속시키는 모든 종류의 자기강화기제 (self-reinforcing mechanism). 빈곤이 대물림되어 지속되고 그 굴레를 끊흐 기 위한 조치가 취해지지 않을 경우, 빈곤의 덫은 자기 강화를 시작한다. 이 러한 부정적인 피드백은 영양결핍, 사회보장 부재, 인구증가, 환경파괴와 불 편등한 경제성장과 같은 환경적 요인을 양산하고, 이들이 다시 강화되는 악 순환이 지속된다(Azariadis and Stachurski 2005).

지금까지 제 2 장에서는 빈곤을 정의하기 위한 접근법을 살펴보았다. 측정의 편리성 과 개념화의 용이성이 큰 장점인 경제적 접근법이 가장 정확하고 객관적인 방법일 것이라는 생각은 대부분 편견에서 비롯된다. 경제적 접근법은 영양실조와 같이 물질 적인 목표를 달성하지 못했을 때 오는 이후의 결과에 대해 분석하지 못하는 한계를 가지고 있다. 이와는 반대로 역량측면의 빈곤은 일반적으로 빈곤의 개념에 포함되지 않을지 모르나 빈곤의 구성요소임에 분명하다. 또한 이러한 역량이 증대할수록 사회 적 박탈은 감소하게 된다. 참여를 통한 접근법은 빈곤에 대한 사회마다 다른 가치를 바탕으로 정의를 가능하게 해주는 데서 그 의미를 찾을 수 있다. 
빈곤의 정의는 빈곤해소 전략수립과 정책결정에 있어 결정적인 영향을 미친다. 이 상 살펴본 여러 가지 접근법 사이의 중첩은 한 가지 접근에만 치우침을 경계하고 있 다. 경제적 접근법이 경제성장이나 재분배를 통한 소득 확대에 중점을 두는 반면, 역 량 접근법은 공공재의 제공을 통한 개인 역량의 확보를 중요시 한다. 반면, 사회적 배제는 차별을 근절하는 정책을 강조한다. 따라서 빈곤을 정의하는데 있어 다면적인 특성을 반영할 수 있는 방법들이 개발되어야 하며 이는 빈곤감소 정책을 수립하고 이행하는 중요한 바탕이 될 것이다.

\section{III. 빈곤의 측정 방식과 한계}

빈곤과 관련된 논쟁 가운데 가장 전형적인 질문은 빈곤을 왜? 어떻게? 측정해야 하는 가 이다. 빈곤을 측정하는 것은 정책입안자들에게 현재 빈곤 상태와 그 심각성 을 알 수 있게 하고, 빈곤감소 정책의 파급효과와 정책방향을 제시하는 역할을 한다. 빈곤을 측정하는 것은 그 객관성을 유지하기 위해 주로 양화(quantification)을 통해 이루어진다. 그러나 앞서 본 바와 같이 빈곤의 다면성을 포함하기 위한 대다수의 측 정은 질적인(qualificative) 방식에 의해 이루어지고 있다. 따라서 빈곤의 측정을 위 해서는 양적이고 질적인 방식을 모두 고려하고 활용해야 한다. 또한 빈곤의 다면성 때문에 서로 다른 측정방식을 채택할 경우 서로 상이한 결과를 도출할 수 있다는 점 을 고려해야 한다(Barnes et al. 2002). 인간의 삶이라는 것이 그 자체로 양적인 측 정이나 웰빙과 빈곤한 삶을 구분하는 과학적 기준을 수립하기 불가능하다 $(\mathrm{Du}$ Toit 2005). 이러한 점을 고려해 볼 때 빈곤을 측정하는 것은 반드시 필요하나, 모든 측 정방식이 완벽한 것은 아니며 각각의 한계를 가지고 있다는 점을 반드시 고려할 필 요가 있다. 따라서 본 장에서는 현재 빈곤을 측정하기 위해서 활용되고 있는 여러 가지 방식을 살펴보고 각각의 특징과 한계를 살펴보기로 한다. 


\section{1. 양적 측정 방식(Quantitative Measurements)}

\section{1) Household Survey(HHS)}

제 I장

HHS는 1979년 시작된 World Bank의 생활수준 측정연구(Living Standard Measurement Study, LSMS) 가 대표적이다. LSMS는 가계의 소득과 소비행태를 기 반으로 정기적으로 실시되어 그 결과는 World Bank의 정책에 반영되게 된다 (Deaton 2003). HHS 사용 시 장점은 국가 차원에서 뿐만 아니라 지역수준에서도 빈곤 상황과 그 차이, 진화의 과정을 주기적으로 파악할 수 있다는 점이다(World Bank, 2001). 문제는 서베이의 특성 상 설문의 설계와 시간의 흐름, 국가적인 특성 에 따라 그 결과가 달라지거나 단순히 숫자로만 비교할 수 없는 정도의 데이터를 얻 을 수 있다는 점이다. 또한 측정과 분석의 단위가 가계(Household)이기 때문에 가정 내 구성원이 모두 평등하게 자원과 기회를 갖고 있다고 전제한다. 따라서 여성과 남 성 구성원, 성인과 아동 간의 전체적인 불평등과 빈곤의 문제는 간과하게 되는 한계 를 내포하고 있다(World Bank 2001).

또한 HHS에서는 소득과 소비 행태를 모두 활용하는데, 소득은 신뢰도가 높은 데 이터를 쉽게 활용할 수 있고, 서베이 이외의 출처를 통해 응답의 질적인 부분을 확 인할 수 있다는 점이 장점으로 꼽히고 있다. 특히 World Bank는 특히 소비데이터를 선호하는데 이는 좀 더 정확하게 기본욕구가 얼마나 충족되는지를 확인할 수 있기 때문이며, 농업 종사자 등 소득 출처가 불분명하고 소득의 변동 폭이 큰 경우 소비 형태가 실제 빈곤의 상태를 반영할 수 있다는 점에서 소비 데이터 활용이 강조되고 있다(Klugman 2002). 그러나 앞서 밝힌 바와 같이 소득이나 소비 어떤 데이터의 활 용이 강조되건 간에 가계 내 구성원 간, 또는 가계 간 필수품에 대한 니즈가 상이하 고 이는 국가 간, 한 국가 내에서의 지역 간, 또는 시기에 따라 달라진다. 이러한 점 을 고려하지 않고 측정하거나 단순히 비교하는 것은 소비예산을 과대계상하거나 빈 곤의 정도를 과소평가하게 되는 오류를 범할 수 있다.

조사 방식과 기준이 국가별, 시기별로 다양하여 직접 비교가 어려운 경우가 발생 한다. 뿐만 아니라, 소득과 소비가 현금으로 이뤄지지 않고(물물교환 등의 비 화폐수 
단이 사용되거나 등), 농업과 산업의 생산량이 계절에 따라 달라질 수 있는 국가에서 는 소득과 소비를 파악하는 것 자체가 불가능 할 수 있다. 또한 가구 별 소득이나 소비 자료는 가구 내의 구성원 간의 차이를 간과하고 있어, 가정 내(또는 사회적으로 야기되는 가족 내) 불평등과 빈곤을 과소평가 할 수 있다.

\section{2) 빈곤선(Poverty Line)}

소득과 소비 빈곤에 관해 신뢰할 수 있는 분석을 얻기 위해 빈곤선을 사용하는 것 은 대단히 효과적이다. 앞서 밝힌 바와 같이 빈곤선은 소득 또는 소비 빈곤의 경계 선(cut off line)이다(Klugman 2002; World Bank 2001). 기본적으로 빈곤선이 결 정이 되면 빈곤선 아래의 인구에 대한 정책을 입안하고 구현하기가 용이해진다. 따 라서 많은 학자들과 연구자들은 소득과 소비 수준을 금전적으로 지표를 만들기 위해 노력해왔다. 소득과 소비를 금전적인 방식으로 표현하는 것이 상대적으로 쉽고 지속 적으로 모니터링하기 용이하다는 장점이 있지만, 빈곤층 내 인구의 소득/소비 격차를 반영할 수 없다는 한계를 내포하고 있다.

가장 대표적인 절대빈곤선은 세계은행의 절대빈곤선이다. 세계은행의 빈곤선은 1990 년 하루소득 1.01 달러로 처음 도입되었다. 1985년의 PPP 자료를 근거로 한 것 으로 이후 2008년 빈곤선이 1.25달러로 상향조정되었다. 절대빈곤선을 설정하는 방 식은 전물량방식(Market Basket)과 반물량방식(Engel) 으로 나눌 수 있다. 전물량방 식은 생활필수품에 대한 최저수준을 설정하고 이를 화폐단위로 하여 합하는 방식으 로, Rowntree 방식이라고도 한다. 반물량방식은 식료품비용이 소비에서 차지하는 비 중이 일정 수준을 넘으면 빈곤층으로 보는 방식이다. Rowntree 방식은 초기의 연구 가 그러하듯 품목을 정하는 기준이 연구자에 따라 매우 주관적일 수 있다는 비판에 직면한다(Veit-Wilson 1986). 반면 반물량방식은 품목 기준에서 객관성을 보장할 수 있고 계측이 간편하다는 장점이 있으나 어떤 비율을 빈곤의 기준으로 삼을지에 대한 과학적 근거가 결여되어있다는 단점이 있다.

이러한 한계를 극복하기 위해 시도되고 있는 것이 여러 개의 빈곤선을 활용하여 여 러 수준의 빈곤을 구분하는 것이다. 이럴 경우 빈곤선은 단순히 빈곤층과 비 빈곤층 
(poor and non-poor)을 구분하기 위해 사용되는 것이 아니라 비금전적인 지표(교육, 보건 등)에 대한 접근성 등에 따라 여러 빈곤선을 그릴 수 있고, 국제적 지표와 국내 적 지표를 활용한 상대빈곤선과 절대빈곤선을 동시에 활용할 수 있다. 또한 소득과 소 비의 기준을 무엇으로 측정할 것인가는 소득금액, 기초식료품 비용(소비) 등을 지표로 삼을 수 있다. 상대적 빈곤선은 $\mathrm{OECD}$ 는 중위소득의 $40 \%, 50 \%, 60 \%$ 지점을, World Bank는 선진국의 경우 평균소득의 $1 / 2$, 개발도상국의 경우 평균소득의 $1 / 3$ 지점을 상 대적 빈곤선으로 정하고 있어 기관 간, 연구자 간 차이가 존재한다. 실제로 이러한 기 준이 과학적인 근거에 기반을 두는가에 대한 논쟁과 논란이 지속되어오고 있는 것도 사실이다. 상대적 절대빈곤이라는 개념도 사용되는데 소득분배 분포 상의 특정비율 즉, 하위 $10 \%$ 또는 $20 \%$ 를 상대적 절대빈곤으로 규정하는 것이다. 이는 사회의 소득 불평등 그 자체를 강조하기 때문에 사회의 불평등 정도가 낮으면 빈곤선에 해당되는 소득기준은 높아지고, 불평등의 정도가 높으면 빈곤선 기준은 낮아진다는 점을 전제하 고 있다. 이 기준에 다르면 사회가 존재하는 한 빈곤은 사라지지 않는 것으로 인식되 어 특별한 정책적 함의를 주지 못할 가능성이 높다는 점이다. 이외에도 주관적 빈곤선 등과 같이 다양한 빈곤선이 존재한다. 가장 단순할 것 같이 보이는 빈곤선도 실제로는 그 기준과 활용에 따라 여러 가지 형태로 사용되고 있음을 알 수 있다.

\section{3) 기타 양적 측정방식}

위에서 살펴본 2가지 방식 이외에도 빈곤 감소를 위한 정책을 입안하거나 시행할 때 사용되고 있는 중요한 양적 측정방식으로는 다음의 3 가지 방식을 들 수 있다.

(1) Head Count Ratio/Index(HCR)

$\mathrm{HCR}$ 은 빈곤을 측정하는데 있어 가장 많이 쓰이는 방법으로, 전체 인구에서 빈곤선 아래의 생활을 하는 인구의 수 또는 비율을 측정하는 방법이다. 수식은 다음과 같다.

$$
H=\frac{q}{n}
$$


여기서 $\mathrm{H}$ 는 빈곤율, $\mathrm{q}$ 는 빈곤선 이하 개인(가구)수를, $\mathrm{n}$ 은 전체 인구(가구)수를 말 한다. 이 방법에서는 우선 특정 사회의 최저생계비를 추정 즉, 빈곤선을 추정한 뒤 소득이 그 수준에 미달하는 인구를 빈곤층으로 정의하고 전체 인구 중 어느 정도가 빈곤층인지를 측정하게 된다.

이는 간단하게 얼마만큼의 인구가 빈곤, 최빈곤의 상태에 놓여있는지 파악할 수 있는 측정방법으로 빈곤의 발생정도를 의미한다(Klugman 2002). 측정방법이 단순한 만큼 빈곤층의 비율 이외의 빈곤의 정도 즉, 측정하려고 하는 빈곤선 이하의 인구 구성에 대해서는 전혀 정보를 주지 못하는 한계를 가지고 있다. 따라서 이미 빈곤선 아래의 삶을 사는 인구가 빈곤의 상태가 더욱 나빠지거나 또는 소득이 증가했다고 해도 빈곤선을 넘지 못하면 이를 $\mathrm{HCR}$ 을 통해서는 측정할 수 없다. 즉, 빈곤지표가 반드시 반영해야 할 소득의 흐름 중 비 빈곤층-빈곤층 또는 빈곤층 간의 소득 이전 과 재분배에 따른 사회 불평등 변화를 반영해야 한다는 Pigou-Dalton의 이전의 공 리3)를 충족시키지 못함을 의미하는 한계를 내포하고 있다.

(2) Poverty Gap Ratio/Index(PGR)와 The Poverty Gap Squared

흔히 사용되는 빈곤의 지표로서 빈곤갭(Poverty Gap, PG)이 있다. PG은 빈곤선 이하 인구의 소득을 빈곤선까지 증대시키기 위해 국민(또는 국내) 총 생산의 몇 \%의 소득이 필요한가를 보여주는 지표이다. 이는 정책적으로 빈곤감소 정책에 소요되는 비용을 산정할 때 이론적인 기초자료로 사용될 수 있다는 장점에도 불구하고, 실제 프로젝트나 정책이 완전효율의 상태를 보일 수 없기 때문에 산출된 금액보다 훨씬 많은 비용이 소요됨은 당연시된다.

또한 같은 방식을 사용하여 빈곤층을 따로 선정하지 않고 소득의 분포를 반영하지 않은 상태로 빈곤선 이하의 인구 모두에게 똑같이 지원해서 빈곤을 제거하는 빈곤퇴

3) 빈곤과 불평등 지수가 가져야 할 특성들은 공리(axiom)라는 형태로 제시된다. 이 공리 는 일종의 규범적 가치와도 연관되는데, 각 공리로 표현되는 내용을 지수에 반영한다 는 것은 공리가 지향하는 가치가 지수를 통해 드러나도록 한다는 뜻이기 때문이다. 피 구-달튼의 공리(Pogou-Dalton axiom)는 고소득자로부터 저소득자로 소득의 이전이 일어나면 불평등지수는 작아져야 한다는 원리이다. 좀 더 자세한 내용과 다양한 공리 에 대한 내용은 Cowell ed.(2003) 참조. 
치를 위한 최대한의 비용도 구할 수 있다. 이때 최대비용대비 최소비용을 빈곤갭지 수(Poverty Gap Index, PGI)이다. 즉, 빈곤감소 또는 퇴치를 위한 최소한의 비용을 산출함으로서 빈곤의 깊이(depth)를 보여주는 측정법이라 할 수 있다. 그러나 PG와 PGI 모두 head count와 마찬가지로 SIDs 빈곤층 내에서의 소득격차를 보여줄 수 없는 한계를 내포하고 있다.

Poverty Gap Squared는 PGI의 한계를 보완하기 위해 고안되었다. 위에서 나온 소득격차를 선명하게 하기 위해 $\mathrm{PG}$ 에 제곱을 하는 방식으로 구현되며 이는 빈곤의 심각도(severity)를 표현해주는 지수이다. 이 방식에서는 빈곤선과 실제 빈곤 인구의 거리뿐만 아니라 빈곤층 사이의 불평등도 나타낼 수 있다(Klugman 2002).

(3) Sen Index

1990년대 이후 많이 인용되고 있는 $\operatorname{Sen}$ 의 빈곤지수는 위의 전통적인 측정방법이 가진 난점을 보완하기 위해 하나의 대안으로 제시되었다. Sen의 빈곤지표 $\mathrm{P}$ 는 빈곤 선 이하의 인구(head count)와 빈곤갭(poverty gap), 그리고 빈곤층 사이의 상대적 불평등의 3 가지측면을 모두 포함하고 있다. Sen의 지수를 수식으로 표현하면 아래와 같다.

$$
P=H[I+(1-I) \times G p]
$$

$\mathrm{H}=$ 빈곤율, I=income gap 비율, $\mathrm{GP}=$ 저소득층 Gini coefficient

Sen지수는 0에서 1까지 나타낼 수 있으며, 0에 가까워질수록 빈곤하지 않다는 것 을 의미한다. Sen지수의 특징은 세 가지 변수 즉 빈곤율, 소득 갭, 불평등의 변화에 민감하게 반응한다는 점이며, 3가지 변수중 하나의 변수 혹은 그 이상의 변수가 변 화하게 되면 Sen지수도 같은 방향으로 변화한다. 결국 현실적으로는 이러한 방향의 변화를 정책에 반영할 수 있다는 점이 특징이며, 이론적으로 빈곤연구를 진일보 시 킨 업적으로 평가받고 있다(Klugman 2002). 
2. 질적 측정 방식: 소득 이외의 지표

빈곤에 대한 양적인 측정 방식만큼이나 질적인 측정 방식도 웰빙을 측정하는데 중 요한 의미를 가진다. 빈곤의 개념 그 자체로만 봐도 질적인 측정방식은 단순히 소득 의 부족이나 소비 지출 뿐만 아니라 보건, 영양상태, 문맹률, 사회적 관계, 치안, 자 존감, 취약성 등 빈곤으로부터 오는 결과물(outcome)을 측정 방식 안에 포함하려 하 고 있다. 따라서 이러한 질적인 방법들은 비-금전적인 측정방식으로 빈곤선을 표현 하려는 시도라 볼 수 있으며, 이러한 지표들은 인간 개발과 삶의 다면적인 측면에서 빈곤을 해결하는데 필요한 자원과 정책을 보여줄 수 있다(World Bank 2001:18-20).

\section{1) 인간개발지수(Human Development Indicators/Index, HDI)}

HDI는 1990년부터 UNDP에서 제공해온 각 국가의 GNI p.c., 교육, 보건(수명)등 을 모아 각국의 인간개발과 선진화 정도를 비교한 지수이다. 〈표 1〉에서 보는 바와 같이 이러한 지표들은 $\mathrm{UNDP}$ 가 빈곤을 바라보는 관점에 근거한 것으로 각각의 지표 들에서 한계선(threshold)을 정하고 이를 모으면 전체적인 인간 발전 정도를 구현할 수 있을 것이라는 전제로 구성되었다.

〈표 1〉 빈곤의 관점과 지표

\begin{tabular}{l|l}
\hline \multicolumn{1}{c|}{ 빈곤의 관점 } & \multicolumn{1}{c}{ 지표의 종류 } \\
\hline 1. 소득 & GNP, 사회 복지 비용, 급여수준, 빈곤선 \\
\hline 2. 기본 요구 관점 & 식수 접근성, 문맹률, 주거환경 및 영향수준 \\
\hline 3. 사회적 배제 관점 & 정치/사회/경제적 빈곤과 불평등 \\
\hline \multirow{2}{*}{ 4. 지속가능한 삼 관점 } & $\begin{array}{l}\text { 취약성, 장채, 가족의 해체, 알코올 중독 등 사회문제 등에 } \\
\text { 초점을 둔 지역사회 활동 관련 지표 }\end{array}$ \\
\hline 5. 인간 개발 관점 & 보건, 기대수명, 영아사망률, 기타 HDI 등 다양한 지표 \\
\hline
\end{tabular}

출처: Davids et al.(2005).

$\mathrm{GDP}$ 나 GNP p.c.는 양적인 또는 경제적인 측정 방식으로 그 자체로 국제적, 지역 적 비교가 가능하다. 이는 특정 국가가 '얼마나 발전 했는가'를 측정하는 방식으로 사 
용된다. 그러나 이렇게 얼마나 발전했는가를 측정하는 것만으로는 경제적 복지 (economic welfare)이외의 경제적 빈곤과 삶의 질을 측정하기는 어렵다(Brown, Burges \& Davies 2009). HDI는 이러한 한계를 극복하고 빈곤의 다면성을 국별 비교 하기 위해 제안되었다. 따라서 $\mathrm{HDI}$ 는 한 국가의 경제적, 사회적 웰빙과 인간 발전의 평균적인 진전 상황(progress)을 측정하고 있다고 볼 수 있다(UNDP 2009). HDI는 이렇게 3 개의 균등하게 가중치가 주어진 지수들이 다음과 과정을 통해 제공된다.

$$
\mathrm{HDI}=\left(\mathrm{I}_{\text {Health }} \cdot \mathrm{I}_{\text {Education }} \cdot \mathrm{I}_{\text {Income }}\right) 1 / 3
$$

- 소득 $=($ 특정국의 GNI p.c. - 최젓값 $) /($ 최고값 - 최젓값 $) \times($ 각 수의 $\log$ 값 $)$

- 보건 $=($ 특정국의 평균수명 - 최젓값 $) /($ 최고값 - 최젓값 $)$

- 교육 $=(2 / 3) \times($ 기대 재학 년 수 $)+(1 / 3) \times($ 평균 재학 년 수 $)$

여기서 최저값과 최대값은 UNDP에서 정한 표준화를 거쳐 〈표 2〉와 같이 제시된다.

\section{〈표 2〉 $\mathrm{HDI}$ 지표의 정규화}

\begin{tabular}{l|l|c|c}
\hline \multicolumn{1}{c|}{ 영역 } & \multicolumn{1}{|c|}{ 지표 } & 최저값 & 최대값 \\
\hline 보건 & 기대수명(년) & 20 & 85 \\
\hline \multirow{2}{*}{ 교육 } & 기대 재학 년 수(년) & 0 & 18 \\
\cline { 2 - 4 } & 평균 재학 년 수(년) & 0 & 15 \\
\hline \multirow{2}{*}{ 삶의 질(소득) } & GNI p.c.(US\$ 2011 PPP) & 100 & 75,000 \\
\hline
\end{tabular}

출처: UNDP(2014b: 2).

기대수명은 과학적으로 입증된 최소 수명인 20세를 최솟값으로, 교육에 있어 최대 값 18 은 일반적으로 모든 국가에서 석사학위를 마치는 연한으로, GNI p.c. 에서는 100 이하는 측정이 안되며, 연간 경제성장률이 $5 \%$ 로 가정했을 때 향후 5 년 이내 달 성되기 어려운 최대값으로 US\$ 75,000를 설정하였다. ${ }^{4)}$

이렇게 측정되어 발표된 2014년 HDI 중 한국의 중점협력국에 관한 지표는〈표 3〉 과 같다. 전통적인 '금전적인 측정방식'인 GNI p.c.간의 차이가 극명하게 드러나고 있음을 확인할 수 있다.

4) 더 자세한 내용은 $\operatorname{UNDP}(2014 \mathrm{~b}: 2)$ 참조. 
〈표 3〉 중점협력국의 $2014 \mathrm{HDI}$ 와 구성 지표

\begin{tabular}{|c|c|c|c|c|c|}
\hline & $\begin{array}{l}\mathrm{HDI} \\
\text { (값) }\end{array}$ & $\begin{array}{c}\text { GNI p.c. } \\
\text { (US\$, } 2011 \text { PPP) }\end{array}$ & $\begin{array}{c}\text { 기대수명 } \\
\text { (년) }\end{array}$ & $\begin{array}{l}\text { 기대 재학 } \\
\text { 년 수(년) }\end{array}$ & $\begin{array}{l}\text { 평균 재학 } \\
\text { 년 수(년) }\end{array}$ \\
\hline 스리랑카 & 0.750 & 9,250 & 74.3 & 13.6 & 10.8 \\
\hline 아제르바이잔 & 0.747 & 15,725 & 70.8 & 11.8 & 11.2 \\
\hline 페루 & 0.737 & 11,280 & 74.8 & 13.1 & 9.0 \\
\hline 콜롬비아 & 0.711 & 11,527 & 74.0 & 13.2 & 7.1 \\
\hline 몽골 & 0.698 & 8,466 & 67.5 & 15.0 & 8.3 \\
\hline 인도네시아 & 0.684 & 8,970 & 70.8 & 12.7 & 7.5 \\
\hline 파라과이 & 0.676 & 7,580 & 72.3 & 11.9 & 7.7 \\
\hline 볼리비아 & 0.667 & 5,552 & 67.3 & 13.2 & 9.2 \\
\hline 우즈베키스탄 & 0.661 & 5,227 & 68.2 & 11.5 & 10.0 \\
\hline 필리핀 & 0.660 & 6,381 & 68.7 & 11.3 & 8.9 \\
\hline 베트남 & 0.638 & 4,892 & 75.9 & 11.9 & 5.5 \\
\hline 동티모르 & 0.620 & 9,674 & 67.5 & 11.7 & 4.4 \\
\hline 캄보디아 & 0.584 & 2,805 & 71.9 & 10.9 & 5.8 \\
\hline 가나 & 0.573 & 3,532 & 61.1 & 11.5 & 7.0 \\
\hline 라오스 & 0.569 & 4,351 & 68.3 & 10.2 & 4.6 \\
\hline 방글라데시 & 0.558 & 2,713 & 70.7 & 10.0 & 5.1 \\
\hline 네팔 & 0.540 & 2,104 & 68.4 & 12.4 & 3.2 \\
\hline 파키스탄 & 0.537 & 4,652 & 66.6 & 7.7 & 4.7 \\
\hline 르완다 & 0.506 & 1,403 & 64.1 & 13.2 & 3.3 \\
\hline 카메룬 & 0.504 & 2,557 & 55.1 & 10.4 & 5.9 \\
\hline 나이지리아 & 0.504 & 5,353 & 52.5 & 9.0 & 5.2 \\
\hline 솔로몬군도 & 0.491 & 1,385 & 67.7 & 9.2 & 4.5 \\
\hline 우간다 & 0.484 & 1,335 & 59.2 & 10.8 & 5.4 \\
\hline 에티오피아 & 0.435 & 1,303 & 63.6 & 8.5 & 2.4 \\
\hline 모잠비크 & 0.393 & 1,142 & 50.3 & 9.5 & 3.2 \\
\hline DR 콩고 & 0.338 & 444 & 50.0 & 9.7 & 3.1 \\
\hline
\end{tabular}

출처: UNDP(2014a). 
$\mathrm{HDI}$ 가 국가별 또는 특정 집단 별 차이(disparity)를 극명하고 보여주고, 또 실제 생활수준에 대한 직관적인 설명이 가능한 지표로 유용하게 활용되고 있다. 그럼에도 불구하고 $\mathrm{HDI}$ 를 구성하는 지표 자체가 임의적이고 지표 간 상호작용도 내포하고 있 다는 비판이 지속적으로 제기되어 온 것도 부정할 수 없다(Ravallion 2002).

\section{2) 인간빈곤지수(Human Poverty Index, HPI)}

$\mathrm{HPI}$ 는 1997년 UNDP가 제시한 각국 빈곤의 척도이다. HPI는 보건, 교육, 삶의 질 의 관점에서 종합적인 '박탈'을 측정한다는 점에서 $\mathrm{HDI}$ 와 같으나 $\mathrm{HPI}-1$ (개발도상국) 과 HPI-2(선진국)로 나누어 개발도상국과 선진국의 빈곤측정의 기준을 달리하여 각 국가별로 생활을 유지하는데 필요한 선택과 기회를 제공받지 못하는 정도를 측정하 는데 주안점을 두고 있었다. HPI는 인간다운 생활을 누릴 수 있는지를 평가하는 다 음의 3 가지 항목으로 나뉘는데, 1) 40세 미만(HPI-2는 60세)의 사망률, 2) 성인 교 육정도, 3) 안전한 물의 확보 정도와 적절한 영양 공급, 보건 서비스에 대한 접근성 등을 기준으로 하였다.

그러나 각 사회별로 박탈의 정도를 측정하려던 본래의 취지와는 달리 이러한 종합 적인(aggregated) 데이터로는 개인, 가구, 집단을 특정하여 그 특성을 파악할 수가 없다는 한계에 직면하게 되었다. 또한 박탈의 측정에 있어 가장 중요한 자유, 치안, 참여, 지속가능성에 대한 위협 등을 계량화하는데 한계를 드러냄으로서 HDI와의 개 념적 차이에도 불구하고 그 결과와 해석이 유사했다. 이에 따라 2009년 인간개발보 고서를 마지막으로 데이터가 제공되었으며, 뒤에 나올 다면적 빈곤지수가 이를 대체 하게 되었다.

\section{3) 다면적 빈곤지수(Multidimensional Poverty Index, MPI)}

UNDP와 영국 옥스퍼드대 빈곤 - 인간개발계획(Oxford Poverty \& Human Development Initiative, OPHI)가 개발하여 104 개 개발도상국들의 데이터를 바탕으 로 2010년 7월 발표한 빈곤지수이다. MPI의 평가대상은 개인이 아닌 가구 (household)이며, 다음의 10 가지 항목에 대해 평가한다. 이러한 가구조사를 통해 박 
탈점수를 측정하고 이 점수가 $1 / 3$ 이상일 경우 다면적 빈곤상태에 있다고 본다. 만 약 $1 / 2$ 이상이면 심각한 다면적 빈곤상태, $1 / 5-1 / 3$ 은 MPI에 근접한 빈곤상태에 있 다고 보며, 가족 구성원만 조사의 대상으로 한다(일시적인 손님이나 친척 제외).

〈표 4>MPI 조사 항목

\begin{tabular}{|c|c|c|}
\hline 영역 & 지표 & 가중치 \\
\hline \multirow{2}{*}{ 교육 } & 학령기 아동의 재학여부 & $1 / 6$ \\
\hline & 가구 구성원의 학력 & $1 / 6$ \\
\hline \multirow{6}{*}{ 삶의 질 } & 전력 접근성 & $1 / 18$ \\
\hline & 도보 30분 이내의 식수 접근성(MDGs 7.8) & $1 / 18$ \\
\hline & 위생시설(MDGs 7.9) & $1 / 18$ \\
\hline & 조리와 난방에 필요한 고체 연료사용 & $1 / 18$ \\
\hline & 마감이 된 바닥 & $1 / 18$ \\
\hline & $\begin{array}{l}\text { 재산 a) 정보접근성 관련(TV, 라디오 등) } \\
\text { b) 이동수단 관련(자전거, 오토바이, 차량 등) } \\
\text { c) 생활관련(냉장고, 축사 등) }\end{array}$ & $1 / 18$ \\
\hline \multirow{2}{*}{ 보건 } & 유아 사망률 & $1 / 6$ \\
\hline & 영양상태 & $1 / 6$ \\
\hline
\end{tabular}

출처: Kovacevic and Calderon(2014:2-5) 재구성.

HPI가 특정 집단이나 지역, 종교인구 등을 구분하여 분석할 수 없었던 한계를 극 복하며 MPI는 가구조사를 기본으로 하고 있기 때문에 이러한 집단화가 가능하다. $\mathrm{MPI}$ 는 빈곤을 다면적으로 평가하여 전반적인 빈곤상태 뿐만 아니라 어느 부문의 상 태가 열악한지를 구체적으로 알려주기 때문에 정책결정자들에게 유용하게 활용될 수 있다. 또한 MPI는 건강이나 교육 상태의 개선 등 단기적으로 소득에 영향을 미치기 힘든 요소들을 잘 포착할 수 있다는 장점도 가지고 있다. 하지만 MPI는 전혀 새로운 아이디어가 아니며 가구조사가 가지고 있는 근본적인 한계 때문에 측정 자체의 신뢰 도를 담보하기가 어렵다는 비판에서 자유롭지 못하다. 


\section{IV. 결론}

이상으로 빈곤을 정의하는 여러 관점과 측정방식 및 그 한계에 대해 살펴보았다. 과거(그리고 현재까지) 빈곤에 대한 연구가 화폐적 측면을 중심으로 이루어진 경향을 보이고 있다. 따라서 주로 빈곤에 관한 연구는 소득이나 지출을 중심으로 하는 분석 이 중심이었으나, 1990 년대 이후 빈곤층의 참여와 사회적 빈곤에 대한 관심이 확산 되면서 다면적인 빈곤 연구가 진행되기 시작하였다. 최근의 논의에서는 경제적인 측 면뿐만 아니라 비경제적 측면에서의 결핍도 감안하여 다양한 관점에서 빈곤에 대한 분석과 정의가 필요하다는 점에서 많은 연구자들이 공감하고 있다. 그러나 다면적 빈곤연구에서 제기되는 이슈는 여러 빈곤 지표들 중 무엇을 선택하고 어떻게 통합할 것인가 가 그 핵심을 이루고 있다. 연구의 주체와 목적에 따라 지표선택이 달라지고, 각 지표들에 대한 가중에서도 합의가 불가능하다. 이와 같은 의견의 불일치는 빈곤 의 개념이 결국은 주관적 판단에 근거하고 있기 때문일 것이다.

지난 2014년 5월 세계은행이 하루 소득 1.25 달러인 '빈곤선'을 1.75 달러 이상으로 올리는 방안을 검토하고 있다는 기사(Financial Times 2014. 5. 10)와 이후의 논란 들은 아직도 빈곤을 정의하는 방식의 정치적, 정책적 함의가 다양함을 보여주고 있 다. 이는 세계은행이 2011년 기준 $\mathrm{PPP}$ 를 평가한 결과 개발도상국의 빈곤선 이하 인 구가 절반으로 감소한 데 따른 것이다.

우리 모두가 아는 바와 같이 이러한 결과가 세계 빈곤층의 실질적 감소를 의미하 는 것은 아니다. 오히려 하루소득 1.25 달러를 기준으로 한 세계은행의 자료가 세계의 빈곤을 반영하는지에 대한 의문을 제기하는 목소리가 커지고 있다. 세계은행이 빈곤 선을 1.75 달러 이상으로 상향조정 하면 빈곤선 도입 이후 20 여년 만에 가장 큰 폭의 조정이나, 2011년 $\mathrm{PPP}$ 를 기준으로 빈곤선을 1.78달러로 높이더라도 세계 극빈층 인 구는 8억7200만 명으로 2005년에 비해 3분의 1 가량 줄게 되고 지역적 분포도 변화 되어 데이터의 신뢰도에 의문을 제기하고 있다(ibid).

이와 같이 빈곤을 정의한다는 것은 처음부터 불가능한 것인지도 모른다. 또한 빈 곤의 종식이라는 것이 가능한 것인가에 대한 의문은 빈곤에 대한 연구를 지속하면 
할수록 심화될 수도 있다. 이러한 가운데 우리는 인간사를 수치로 표현하거나 측정 하는 것이 불가능함을 인정하면서, 무엇을 위해 이러한 측정이 필요한 것인지를 놓 치지 말아야 할 것이다. 


\section{참고문헌}

Alkire. S.(2002). "Valuing Freedoms: Sen's Capability Approach and

Poverty Reduction』London: Oxford University Press.

Atkinson, A. (1998). "Social Exclusion, Poverty, and Unemployment," in

Atkinson and Hills(eds.) 『Exclusion, Employment and

Opportunity』. LSE Case paper 4. London: LSE.

Azariadis, C. and Stachurski, J.(2005), "Poverty Traps", in eds. P Aghion and S Durlauf ${ }^{\mathbb{H}}$ Handbook of Economic Growth』

North-Holland: Elsevier.

Barnes, M., Heady. C., Middleton, S., Millan, J., Papadopolous, F. \& Tsakloglou, P.(2002). Poverty and Social Exclusion in Europe. Northampton, Mass.: Edward Elgar.

Brown, S., Burges. A. \& Davies, U. 2009. "The Economist: Pocket World in Figures』. London: Profile Books Ltd.

Chambers, R.(1994). "The Origins and Practice of Participatory Rural Appraisal," World Development, Vol. 22.

(1995). "Poverty and livelihoods: "Whose Reality Counts?"

Environment and Urbanization, Vol. 7, No. 1. pp. $173-204$.

Cowell, F. A. ed.(2003). 『The Economics of Poverty and Inequality』 vol.1-2, Edward Elgar.

Davids, I., Theron, F. \& Maphunye, K.J.(2005). "Participatory Development in South Africa: A development management perspective』. Pretoria: Van Schaik Publishers.

Deaton, A.(2003). "Health, Inequality, and Economic Development," Journal of Economic Literature, Vol. XLI. pp. 113-58.

De Beer, F. and Swanepoel, H.(2000). Introduction to development Studies. Pretoria: J.L. van Schaik.

Du Toit, A.(2005). "Poverty Measurement Blues." CPRC Working Paper 55. Cape Town: PLAAS \& CPRC. 
Estivill, J.(2003). ${ }^{\circledR C}$ Concepts and Strategies for Combating Social Exclusion. An Overview』. Geneva: ILO Office(Available at

http://www.ilo.org/public/libdoc/ilo/2003/103B09_267_engl .pdf, access data: 2015/02/16).

European Commission(2004). "Joint report by the Commission and the Council on social inclusion", Brussels: EC.

Haralambos, M.; Holborn, M. \& Heald, R. (1991). "Sociology: Themes and Perspectives』. London: Collins Educational.

Joseph Rowntree Foundation(2013). ${ }^{\mathbb{N}}$ Monitoring Poverty and Social Exclusion 2013』. London: JRF

Joseph, K. and J. Sumption(1979) 『Equality』London: John Murray Publishers.

Klugman, J.(2002) ${ }^{\circledR}$ A Sourcebook for Poverty Reduction Strategies』 Washington DC: World Bank.

Kovacevic, M. and M. C. Calderon(2014). "UNDP's Multidimensional Poverty Index: 2014 Specifications”, Occasional Paper, New York: UNDP Human Development Report Office(Available at http://hdr.undp.org/sites/default/files/specifications_for_c omputation_of_the_mpi.pdf, access date: 2015/02/16).

Lauer, R.(1998). 『Social Problems and the Quality of Life』. Boston: Mc Graw-Hill.

Le Grand, J.(1991). "Quasi-Markets and Social Policy," The Economic Journal, Vol. 101, No. 408. pp. 1256-67. (Available at http://www.jstor.org/stable/2234441, access data: 2015/02 /16).

Lister, R.(2004). 『Poverty: Key Concepts』. Cambridge: Polity Press. Lipton, M.(1997) "Defining and Measuring Poverty: Conceptual Issues," in UNDP Human Development Papers, New York: UNDP. Mullin, W.and M. Arce(2008). "Resilience of Families Living in Poverty, Journal of Family Social Work, Vol. 11(4). pp. 424-40. 
Narayan, D.(2002) 『Empowerment and Poverty Reduction: A Sourcebook』. Washington DC: World Bank.

Ravallion, M.(1992), "Poverty freak: a guide to concepts and methods", Living Standards Measurement Papers, Washington DC: The World Bank.

.(1994) 『Poverty Comparisons: Fundamentals of Pure and Applied Economics』. London: Routledge.

(2002). 『The Debate on Globalization, Poverty and Inequality: Why Measurement Matters』. Washington DC: World Bank.

Ravallion, M., Chen, S.(2008), "The developing world is poorer than we thought, but no less successful in the fight against poverty", Policy Research Working Paper Series, NO. 4703, Washington DC: The World Bank.

Ravallion, M., Shaohua, C., Sangraula, P.(2009), "Dollar a day", The World Bank Economic Review, 23(2), pp. 163-184.

Ringen, S.(1987). "The Possibility of Politics』. Oxford: Clarendon Press.

Rowntree, S. (1901). 『A Study of Town Life』. London: Longman.

Shaffer, P.(1996). "Beneath the Poverty Debate: Some Issues," IDS Bulletin. 27.

Sen, A. (1983) "Poor, Relatively Speaking." Oxford Economics Paper, Vol. 35. pp. 153-69.

(1999). 『Development as Freedom』. New York: Sage.

Spicker, P.(1993) 『Poverty and Social Security』London: Routledge.

Townsend, P.(1979) "Poverty in the United Kingdom』. London: Allen Lane and Penguin Books.

(1993) 『The International Analysis of Poverty』. Hemel Hempstead: Harvester Wheatsheaf.

United Nations. (1995) "The Copenhagen Declaration and Programme of Action," World Summit for Social Development, New York: UN. 
United Nations Development Programme(various years) Human Development Report. New York: UNDP. (2014a). Human Development Report 2014. New York: UNDP. (2014b). Human Development Report 2014: Technical Note: New York: UNDP.

Veit-Wilson, J. H.(1986) "Paradigms of Poverty: A Rehabilitation of B.S. Rowntree," Journal of Social Policy. Volume 15. Issue 01. pp 69-99.

World Bank(various years). "World Development Report 2000/2001』 Washington DC: World Bank. 